\title{
Applied Learning Through the Management of Online Educational Resources
}

\author{
Pradeep Charath \\ B.Tech and MBA Candidate \\ Grand Valley State University, Allendale Michigan \\ Christina DeKoekkoek \\ BBA in Accounting Candidate \\ Grand Valley State University, Allendale Michigan \\ Maris Stella (Star) Swift \\ JD and MLIR, Professor Seidman College of Business \\ Grand Valley State University, Grand Rapids Michigan
}

\begin{abstract}
The purpose of the website, The Digital Workplace, was originally to educate individuals on how the increasing digitalization of the workplace affects business owners and employees, especially regarding the law. Since then the website has evolved to encompass many topics where technology and the law intersect, including cloud storage, privacy, free speech, and security. The site explains the law using cases as examples, with summaries, links to court documents, and videos. The site also explains technology with explanations on types of data storage, how to secure data, and data definitions. The website initially drew a lot of traffic from local students using it as a guide for their classes. When we received the Google AdWords Grant and began advertising the website usage increased. The Google AdWords Grant has given the website a global reach. Countries such as India, the Philippines, South Africa, and the United Kingdom are frequent visitors. One thing all these countries have in common is that they are all affected by the technological revolution and it impacts all their workplaces. The issue of how to manage a growing amount of data is universal along with the questions of privacy and security that come with any data management. In today's world, cases involving technology are at the forefront of human rights; it is important to provide accessible information to people on the law in a format that they can understand.
\end{abstract}

Keywords: AdWords, Analytics, Online Learning, Collaboration, Law in Technology

\section{PURPOSE}

The purpose of the website, The Digital Workplace, was originally to educate individuals on how the increasing digitalization of the workplace affects business owners and employees, especially regarding the law. Since then the website has evolved to encompass many topics where technology and the law intersect, including cloud storage, privacy, free speech, and security. The site explains the law using cases as examples, with summaries, links to court documents, and videos. The site also explains technology with explanations on types of data storage, how to secure data, and data definitions.

The website initially drew a lot of traffic from local students using it as a guide for their classes. When we received the Google AdWords Grant and began advertising the website usage increased. The Google AdWords Grant has given the website a global reach. Countries such as India, the Philippines, South Africa, and the United Kingdom are frequent visitors. One thing all 
these countries have in common is that they are all affected by the technological revolution and it impacts all their workplaces.

The issue of how to manage a growing amount of data is universal along with the questions of privacy and security that come with any data management. In today's world, cases involving technology are at the forefront of human rights; it is important to provide accessible information to people on the law in a format that they can understand.

\section{BACKGROUND}

The managers of the website are a group called Teaching through Technology. At its core, Teaching through Technology ( $\mathrm{t} 3$ ) is a multi-faceted, community organization comprised of university students, alumni and faculty, who all share a passion for providing access to free resources to better the lives of others. The group was founded by a university professor in 2008 as an open source nonprofit organization providing free and accessible learning to the global community. Since then the group has expanded to include faculty, current students, and alumni at a public Midwestern institution in the United States. The team's products take the shape of multiple websites, a few apps, and podcasts that range from details about the law, the workplace, midwifery, solar-powered technology and the LGBTQ community. This paper will focus on the Digital Workplace site on the law and technology.

\section{EVOLUTION OF PURPOSE}

Through the creation of the website, the site directors realized that the purpose of the site was not limited to educating other people. Everyone involved learned through the operation of the website. The directors of the site learned the content of the cases as they summarized them and posted videos and other information to the site. They also learned how to utilize the Google AdWords Grant and how to interpret the analytics to make changes for the website. These changes came in both the form of tailoring content to meet the demand for topics and in updating ad campaigns to better target the site's audience. These three aspects form an interdependent triangle of analytics, content, and ads that reinforce each other. The integrity of the site relies on the optimal performance of all three of these areas in connection with one another.

Over the years, the site has seen a multitude of changes as the directors have learned how to make a more user friendly and effective experience. In addition, there have been challenges and changes in keeping up with the evolving rules of Google Grants. Learning how to adapt to these changes and how to broaden the appeal of the site has led to learning outside of the anticipated subject of study.

\section{ORGANIZATION}

The website itself is organized around four main topics, with plans to add a fifth section on artificial intelligence (AI). The first topic is cases revolving around search and seizure and privacy rights. This includes explaining what employers can and cannot legally monitor about their employees. Case examples include, among other issues, whether or not employers can legally read employee emails on their server, warrants to search cell phones, and tech companies being ordered to build software allowing the government to circumvent passcode protections.

The second topic is related to the first because it explains electronic information and its storage. This is relevant because of privacy concerns and data security. The site focuses on explaining what cloud storage is through an informational video. There is also a link to a sample cloud contract [1] outlying the most important considerations for cloud storage. 
The third topic is e-discovery. E-Discovery is used by the parties to a lawsuit, an administrative hearing or an arbitration. In federal and state courts there are rules that specifically require the parties to disclose electronic information [2] that is relevant to the lawsuit. This electronic information (data) may be stored on a computer hard drive, a flash drive, an e-mail server, a cloud, etc. The site walks users through each step in the e-discovery process.

The last topic on the site, as of the moment, is free speech concerns. This focuses on cases such as Elonis vs. United States [3], where it was ruled that violent posts on Facebook do not constitute as a threat unless there is intent. The site also examines the line between freedom of speech on social media and cyber harassment.

Typically, each case is given a video explaining the case, an abstract summarizing what the case was about and what the results were, the original court documents for people to read for themselves, and some links for further learning and more information. Cases that are in progress are consistently updated with new information on the outcome of the case.

\section{WHY E-LEARNING?}

The internet is one of the fastest growing forms of media. With over half the world's population using the internet [4] as of January 2018, which is a significantly higher level than previously projected [5]. Due to the versatile nature of the exchange of information through the internet, as a medium, it serves as an ideal method of sharing knowledge-based content.

According to Gros and García-Peñalvo (2016), e-Learning describes learning delivered fully online where technology mediates the learning process, teaching is delivered entirely via Internet, and students and instructors are not required to be available at the same time and place [6]. The practice of e-learning matches with various pedagogical models and the evolution of e-learning has led to modernizing pedagogy.

The pedagogies of e-learning may be categorized into four categories, namely; associative, cognitive/constructivist, situative and connectivist [7]. Associative learning is the traditional form of educating, with a strong focus on the individual, mostly based on learning through association and reinforcement. Cognitive/Constructivist learning has a more dynamic and broad view of knowledge, and is mostly a task oriented form of learning. Situative learning is "learner centered" and learning is viewed as a social practice refined through social interaction. Connectivist Learning is the distribution of a knowledge across the web in multiple environments, the engagement with a networked environment serving as the educator.

This project utilizes three of the four of these pedagogy methods. The foundation of our website is built upon connectivist learning. Visitors to the site are given a variety of links to gather further information on topics they are interested in learning about and the original source documentation for cases. The researching done by the directors of the site to collect links and news about cases is another use of connectivist learning. The case summaries and videos take the more traditional associative learning approach, a form of chalk talk. The directors experience constructivist learning through the constant adaptation to new information given by analytics and changes in Google AdWords grant guidelines. Figure 1 shows a visual representation of the aforementioned pedagogy methods. 
Figure 1: Graphical Representation of the Used Pedagogy Methods
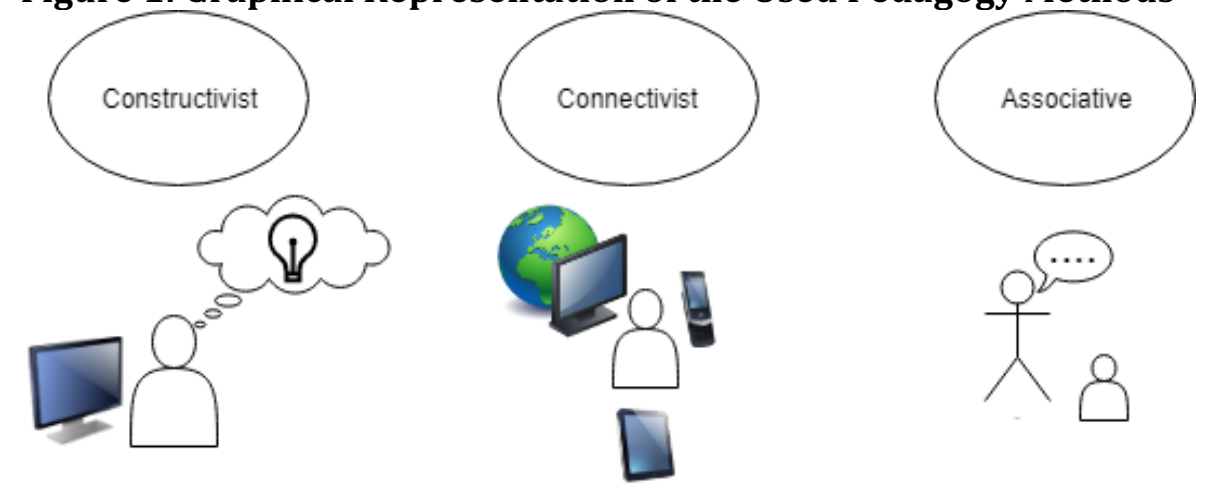

\section{Individual Impact - Website Directors}

IMPACT

The creation, operation and maintenance of the website allowed for the directors to learn the subject matter, new practices of research and the technological aspects of the website. The content learned revolved around the facts and proceedings of the cases and the legal implications of each case. Determining how to obtain court documents and how to summarize cases appropriately were new practices that had to be adopted. The requirements of developing the structure of the website and formatting the data and media in an organized manner were integral to the technological learning. Editing the data to optimize learning was also imperative.

\section{Organizational Impact - All members of T3}

The larger Teach through Technology group learned from one another what practices work best for management of websites and the new content posted on the websites. Students from all different disciplines learned how to collaborate with one another and with alumni and faculty. The strengths of each area of learning come together to build a stronger product and give outside input on details the site managers may have overlooked. Each member brings to the table their own perspective and learning from one another.

\section{University-level Impact}

The resources provided on the legal aspects of technology in the workplace are used to instruct university students as a textbook. The summaries and videos on the website allow the students to learn the legal implications of real cases in a visual and auditory manner. The online form of the resources enables them to be accessed from any computer or suitable mobile-device. The availability of the content provides students with the option to control the time and pace of learning. Feedback on the experience of using the website is actively sought during the course which is considered for future improvements.

\section{Impact on the Greater Community}

The website provides relevant and detailed legal information for the increasingly digitized workplace. It also provides video instruction of cases dealing with employee and employer responsibilities when technology is involved. As a teaching tool, the website allows for this information to be curated and delivered directly to any interested visitor. The latest administrative rules and regulations regarding technology are also included in the website for quick and easy access for the user. 


\section{ROLE OF GOOGLE ADWORDS AND ANALYTICS}

Through the Google Grant, T3 receives $\$ 10,000$ every month in advertisements that appear with the results from the Google search engine. The advertisements appear when specific phrases are searched that match the specified keywords and match-type. The advertisements provide links to redirect users to the Digital Workplace website and at this time, the grant money is deducted. The amount that is deducted is decided based on a cost-per-click bidding process with a maximum of $\$ 2$ [8]. The specifications of the ads and the keywords are assigned and controlled using Google AdWords.

The performance and reach of the ads established through Google AdWords are monitored using Google Analytics. Google Analytics also provides data on the interaction users have with the website. This data serves as an invaluable resource to determine the necessary course of action to be taken to optimize the website for better user experience. Figure 2 indicates the necessity the website has in the Google AdWords Grant.

\section{Figure 2: Graphical Representation of the Used Pedagogy Methods}
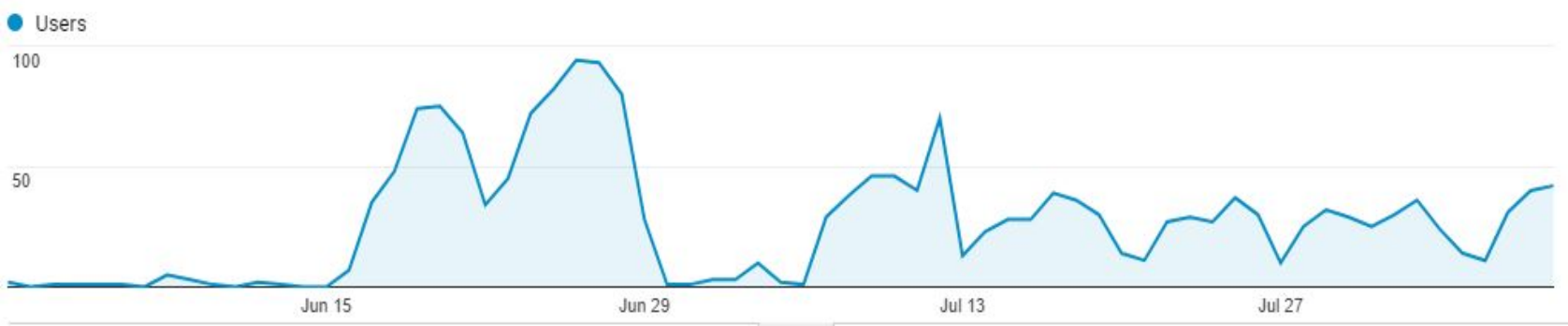

Prior to June $15^{\text {th }}$ 2018, the Google AdWords account was deactivated for a period of time. It is clear from the data that the traffic to the website was significantly lower when the AdWords account was done compared to when the advertisements were being displayed. Subsequent to June $29^{\text {th }}$ 2018, certain actions were taken with the geographic targeting of the ads which proved to be detrimental to traffic. Reversing those actions allowed for the process of restoring the previous level of traffic to begin.

Key terms pertaining to Google AdWords [9]:

- Google AdWords: The Google provided program, used for managing Ad Campaigns and creating Ads.

- Google Ad Campaign: A division within a Google AdWords account. Each campaign can be allocated a specific dollar amount and can be targeted towards a specific geographic region.

- Google AdGroup: A group of similar ads all connected to the same list of keywords, an AdGroup is made within an Ad Campaign.

- Impressions: The number of Google searches that the ad created has appeared in.

- Clicks: The number of clicks the Google Ad has received.

- Cost Per Click: The cost associated by a click on a Google Ad.

- Click Through Rate: Ratio of how many people click on your advertisement divided by the number of views the ad had (impressions).

Some other important terms to know in order to understand Google Analytics are as follows:

- Bounce Rate: Percentage amount given to single page visits or visits in which the person left your site from the entrance (landing) page. (Google AdWords)

- Average Visit Duration: The average amount of time spent on webpage. 
- Keywords: The search term used when people use a Google search engine.

- In Page Analytics: Breakdown of the webpage, displaying what areas are getting the most clicks.

Overtime these analytics have shaped the way the directors organize and choose content for the website. For example, site directors noticed that ads related to the topic of Free Speech on Social media had a high click through rate, leading directors to post more content on cases related to free speech versus what constitutes as a threat.

The directors have also faced challenges with adapting to changing guidelines for what is required for Google AdWords grants. Rules on whether keywords must be single words or phrases, how ads must be targeted and quality score thresholds for ads are constantly changing and the ads must change with them. A new rule was set requiring a minimum click through rate of 5 percent [10], giving the team the need for ads that are more effective. While in the past, quantity of ads through an increased budget was the focus, now the team is learning how to create better ads on a lower budget.

\section{Content}

\section{CONCLUSION}

The managers of the website have worked together to decide the content that should be included in the website, the level of detail of said content and the form in which it was to appear. Monitoring the changes and latest news surrounding technological cases was seen as the driving factor for updating the content. It was observed that although the workplace was the area of focus, many non-workplace cases were found to be relevant to the purpose of the website. This was due to the personal use of technology in the workplace as well as the impact cases regarding private use of technology had overall.

\section{Ads, Bounce rate (Google Analytics)}

The performance of the ads and keeping up with the changes to the technical requirements of the grant constituted the major challenges regarding the online marketing of the website. Bounce rate was the major performance measure of the website itself along with average duration per visit whereas the performance of the ads was measured based on its CTR, total number of clicks and quality score. The significant drop in bounce rate was an indicator that the website had been performing well. In addition to the effectiveness of the ads, the privacy of the data subjects has become one of the primary elements of data processing.

\section{Global Reach}

The website was visited by users from various locations around the world as shown by the analytics. This supported the notion that the e-learning format adopted would provide quick and easy access. It also implied that the selected content was of interest to people all around the world.

\section{Learning by Creating Knowledge and the Website}

The creation of the website, research into the content and formatting the relevant information for the optimal learning experience allowed the directors of the website to learn from the process. Deeper understandings of the technical aspects as well as the latest developments in the real-life applications of technology were obtained which are necessary skills for professional careers in the future. The directors observed that the importance of the legal understandings of the digital workplace would need to be extended to the digital world. The advancements in the technological capabilities has brought changes to the perception of data. 
Therefore, there is now a need for clear definitions of the various data entities, such as personal information on social media and genetic codes, and their legal standings.

\section{References}

Digital Workplace, "Cloud Storage”, Retrieved from http://digitalworkplace.teachthroughtech.org/about/cloudstorage/

Shook Hardy \& Bacon, (2018). "Links to State Court and Local Federal eDiscovery Rules: Data and Discovery Strategies". Retrieved from https://www.shb.com/ /media/files/services/practices/dataanddiscoverystrategies/state-court-and-localfederal-ediscovery-rules.pdf

Digital Workplace, "Elonis Vs United States": Retrieved from http://digitalworkplace.teachthroughtech.org/sample-page/communications/free-speech-on-social-media/

Kemp, S., (2018). "Digital in 2018: World's Internet Users Pass the 4 Billion Mark”, We Are Social Ltd. Retrieved from https://wearesocial.com/blog/2018/01/global-digital-report-2018

Statista, "Worldwide internet user penetration from 2014 to 2021". Retrieved from https://www.statista.com/statistics/325706/global-internet-user-penetration/

Gros, B. \& García-Peñalvo, F.J., (2016). "Future Trends in the Design Strategies and Technological Affordances of ELearning". Retrieved from https://link.springer.com/content/pdf/10.1007/978-3-319-17727-4_67-1.pdf

Conole, G. (2014) “Learning design: A practical approach” London: Routledge. Retrieved from https://link.springer.com/content/pdf/10.1007/978-3-319-17727-4_67-1.pdf

Google Ad Grants Help, "Bid Limit”. Retrieved from https://support.google.com/grants/answer/1332166?hl=en

Andrykovich, K., Wisniewski, E. \& Swift, M. S. (2014) “How a Google Grant and Google Analytics Improved a Website: A Case Example of a University's Arbitration and Mediation Website Used by Students, Business and the Public", International Journal of Business Administration, Vol 5, No. 4 pp 60-69

Google Ad Grants Help, "Performance". Retrieved from https://support.google.com/grants/answer/117827?hl=en 